\title{
The VEGF -634G>C promoter polymorphism is associated with risk of gastric cancer
} Xiaoxiang Guan ${ }^{1}$, Hui Zhao ${ }^{1}$, Jiangong Niu ${ }^{1}$, Dongfeng Tang ${ }^{2}$, Jaffer A Ajani ${ }^{3}$ and Qingyi Wei*1

Address: ${ }^{1}$ Department of Epidemiology, the University of Texas M. D. Anderson Cancer Center, Houston, Texas 77030, USA, ${ }^{2}$ Department of Pathology, the University of Texas M. D. Anderson Cancer Center, Houston, Texas 77030, USA and ${ }^{3}$ Department of Gastrointestinal Medical Oncology, the University of Texas M. D. Anderson Cancer Center, Houston, Texas 77030, USA

Email: Xiaoxiang Guan - xguan@mdanderson.org; Hui Zhao - huizhao@mdanderson.org; Jiangong Niu - jniu@mdanderson.org; Dongfeng Tang - dtan@mdanderson.org; Jaffer A Ajani - jajani@mdanderson.org; Qingyi Wei* - qwei@mdanderson.org

* Corresponding author

Published: 16 October 2009

BMC Gastroenterology 2009, 9:77 doi:10.1 I86/I47|-230X-9-77

This article is available from: http://www.biomedcentral.com/I47/-230X/9/77

(c) 2009 Guan et al; licensee BioMed Central Ltd.

This is an Open Access article distributed under the terms of the Creative Commons Attribution License (http://creativecommons.org/licenses/by/2.0), which permits unrestricted use, distribution, and reproduction in any medium, provided the original work is properly cited.

\begin{abstract}
Background: Both TGF- $\beta$ I and VEGF play a critic role in the multiple-step process of tumorgenesis of gastric cancer. Single nucleotide polymorphisms (SNPs) of the TGFBI and VEGF genes have been associated with risk and progression of many cancers. In this study, we investigated the association between potentially functional SNPs of these two genes and risk of gastric cancer in a US population.

Methods: The risk associated with genotypes and haplotypes of four TGFB/ SNPs and four VEGF SNPs were determined by multivariate logistic regression analysis in 171 patients with gastric cancer and 353 cancer-free controls frequency-matched by age, sex and ethnicity.

Results: Compared with the VEGF-634GG genotype, the -634CG genotype and the combined $634 C G+C C$ genotypes were associated with a significantly elevated risk of gastric cancer (adjusted $\mathrm{OR}=1.88,95 \% \mathrm{Cl}=1.24-2.86$ and adjusted $\mathrm{OR}=1.56,95 \% \mathrm{Cl}=1.07-2.27$, respectively). However, none of other TGFBI and VEGF SNPs was associated with risk of gastric cancer.

Conclusion: Our data suggested that the VEGF-634G>C SNP may be a marker for susceptibility to gastric cancer, and this finding needs to be validated in larger studies.
\end{abstract}

\section{Background}

Gastric cancer is one of the major causes of cancer-related deaths worldwide, although both incidence and mortality of gastric cancer have been declining in recent years [1]. In 2008 , there were 21,500 new gastric cancer patients, and 10,880 patients died of this disease in the United States [2]. Epidemiological studies have identified many risk factors for gastric cancer, including older age, being a man, Helicobacter pylori ( $\mathrm{H}$. pylori) bacteria infection, diets high in smoked foods, salted fish and meats, and pickled vegetables, tobacco use and obesity [2]. Although about two-thirds of gastric cancer could be prevented by changing lifestyle and diet habits [3], the fact that some individuals develop gastric cancer while others do not when having similar exposures suggests that genetic factors may also play an important role in the etiology of gastric cancer. 
It has been reported that both TGF- $\beta 1$ and VEGF played an important role in the oncogenesis of gastric cancer [4,5]. Both TGFB1 and VEGF genes are highly polymorphic, reportedly having 168 and 140 variants, respectively, but few are within the promoters or coding regions that may be potentially functional http:// www.ncbi.nlm.nih.gov/SNP/. Of these variants, several common single nucleotide polymorphisms (SNPs) have been described as important [6-8] and reported to be involved in the etiology of various cancers [9-12]. For example, some TGFB1 and VEGF variants are associated with protein functions, which may contribute to an individual's susceptibility to cancer [13]. Several studies have investigated the association between TGFB1 and VEGF SNPs and risk of cancers, including breast cancer [14-16], lung cancer $[17,18]$, and gastric cancer [19-22], but the results were inconsistent.

To investigate the role of TGFB1 and VEGF SNPs in the etiology of gastric cancer, we conducted a case-control study to evaluate the association between three TGFB1 SNPs (one promoter SNP $-509 \mathrm{C}>\mathrm{T}$ and two exon 1 SNPs $+869 \mathrm{~T}>\mathrm{C}$ and $+915 \mathrm{G}>\mathrm{C}$ ) and three VEGF SNPs (one promoter SNP -1498T>C, one 5'-untranslated region SNP $634 \mathrm{G}>\mathrm{C}$ and one 3'-untranslated region SNP +936C $>\mathrm{T}$ ) and gastric cancer risk in a US population.

\section{Methods \\ Study population}

The case-control study consisted of 171 patients with newly diagnosed and histologically confirmed gastric cancer at The University of Texas MD Anderson Cancer Center (Houston, TX) between February 1990 and July 2008. The 353 cancer-free controls subjects were selected from an ongoing molecular epidemiology study of the head and neck cancer since 1995 [23] by frequency matching by age, sex and ethnicity. All cancer-free control subjects were recruited from persons who were not hospital patients, nor seeking health care but accompanying the patients visiting the clinics, and who were genetically unrelated to the cases. The study protocol and informed consent form used in this study were approved by our institutional review board.

\section{Genotyping}

Genomic DNA was extracted from the buffy coat fraction of each blood sample by using a Blood Mini Kit (Qiagen, Valencia, CA) according to the manufacturer's instructions. DNA purity and concentrations were determined by spectrophotometric measurement of absorbance at 260 and $280 \mathrm{~nm}$ by UV spectrophotometer.

The selected three TGFB1 SNPs [-509C $>$ T (rs1800469) in the promoter, $+869 \mathrm{~T}>\mathrm{C}(\mathrm{rs} 1800470)$ and $+915 \mathrm{G}>\mathrm{C}$ (rs1800471) in the exon 1] and three promoter VEGF
SNPs [-1498T>C (rs833061) in the promoter and 634G>C (rs2010963) in the 5'-untranslated region, and VEGF +936C $>T$ (rs3025039) in the 3'-untranslated region] were genotyped using polymerase chain reactionrestriction fragment length polymorphism (PCR-RFLP) method. These six SNPs are relatively common (a minor allele frequency $>0.05$ ) in Caucasian populations. Genotypes of TGFB1 SNPs were determined as previously described [24]. Assays on the VEGF-1498T>C (rs833061), $-634 \mathrm{G}>\mathrm{C}$ (rs2010963), and +936C >T (rs3025039) SNPs were previously reported [17]

For the PCR-RFLP assay, the genotyping was performed without knowing the subjects' case and control status, and almost the same number of cases and controls were assayed in each 96-well PCR plate. Two research assistants independently read the gel pictures and performed the repeated assays, if they did not reach a consensus on the tested genotype. In addition, $10 \%$ of the samples were randomly selected to perform the repeated assays, and the results were $100 \%$ concordant.

\section{Statistical Analysis}

The $\chi^{2}$ tests were used to compare the distribution of demographic variables and selected risk factors between cases and controls. The Hardy-Weinberg equilibrium $\left(\mathrm{p}^{2}+2 \mathrm{pq}+\mathrm{q}^{2}=1\right)$, where $\mathrm{p}$ is the frequency of the variant allele and $\mathrm{q}=1$-p, was tested by a goodness-of-fit $\chi^{2}$ test to compare the observed genotype frequencies with the expected genotype frequencies in cancer-free controls. Unconditional logistical regression analysis was used to calculate odds ratios (ORs) and their 95\% confidence intervals (CIs) with and without adjustment for age, sex, ethnicity, smoking status and alcohol use. Age was also dichotomized according to the median age ( 57 years) of the controls. The logistic regression model was also used for the trend test of the genotypes with different number of the minor alleles. The 2-linkage disequilibrium (LD) program and Proc ALLELE in SAS/Genetics software were used to detect the LD of any pair of SNPs. Proc HAPLOTYPE in SAS/Genetics software using the expectation-maximization (EM) algorithm was applied to generate maximum likelihood estimates of haplotype frequencies. Haplotype were combined when their frequency was $<5 \%$. The joint effects of the TGFB1 and VEGF SNPs and their interactions with smoking and drinking on gastric cancer risk were also evaluated. Finally, we calculated the false-positive report probability (FPRP) to test for falsepositive associations, using prior probabilities of 0.0001 , $0.001,0.01,0.1$, and 0.25 . The OR was set close to the observed value obtained in our study, and a probability of $<0.2$ was considered a noteworthy association. All statistical tests were two-sided, with a $P$ value of 0.05 considered significant, by using SAS software (version 9.1; SAS Institute, Cary, NC). 


\section{Results \\ Characteristics of the study population}

This analysis included 171 gastric cancer cases and 353 cancer-free controls. Because we used frequency matching, there were no significant difference in distributions of age, sex and ethnicity between the cases and controls $(P=$ $0.135,0.444$ and 0.486 , respectively). For the tumor types, more than $50 \%$ of the cases had intestinal type, about 125 had difuse type, and the remaining was mixed. There were more current and former smokers in cases (19.9\% and 39.2\%, respectively) than in controls $(13.6 \%$ and $38.5 \%$, respectively), but the difference was not statistically significant $(P=0.126)$. However, there were significantly more alcohol drinkers among cases than among controls $(P=0.037)$ (Table 1$)$. These variables were further adjusted for in multivariate logistic regression models to control for any residual effect of their confounding on the main effect of selected SNPs.

\section{TGFBI and VEGF genotypes and risk of gastric cancer}

The genotype and allele distributions of the three TGFB1 SNPs and three VEGF SNPs between the cases and controls are summarized in Table 2. The observed genotype frequencies of these SNPs were all in agreement with the Hardy-Weinberg equilibrium in the control subjects, except for TGFB1 -509C>T and VEGF -634G>C, indicating some possible selection bias in the hospital-based controls. Although none of the minor alleles had a different frequency distribution between the cases and the controls, the VEGF-634G>C genotype frequencies were statistically significantly between the cases (40.4\% for GG, $42.1 \%$ for CG, and $17.5 \%$ for CC) and the controls (51.0\% for GG, $28.0 \%$ for CG and $21.0 \%$ for CC) $(P=0.003)$ (Table 2$)$.

Further logistic regression analysis revealed that, of the six SNPs examined, only the VEGF -634CG heterozygous and the combined -634CG+CC variant genotypes were associated with a significantly elevated risk of gastric cancer (adjusted OR $=1.88,95 \% \mathrm{CI}=1.24-2.86$ and adjusted OR $=1.56,95 \% \mathrm{CI}=1.07-2.27$, respectively). In further stratified analysis by age, sex, ethnicity, alcohol use and smoking status, the risk associated with the combined 634CG+CC variant genotypes was more evident in subgroups of ever smokers (adjusted $\mathrm{OR}=1.75,95 \% \mathrm{CI}=$ 1.06-2.90), never drinker (adjusted OR $=2.00,95 \% \mathrm{CI}=$ 1.14-3.54) and non-white subjects (adjusted OR = 2.39, $95 \% \mathrm{CI}=1.15-4.98$ ) (Table 3 ). This kind of significant association was not found for the three TGFB1 SNPs and other two VEGF SNPs (Table 2).

\section{TGFBI and VEGF haplotypes and risk of gastric cancer}

To further analyze possible combined effects of the TGFB1 and VEGF SNPs, we estimated the haplotypes on the basis of the observed genotypes. As shown in Table 4, the four common TGFB1 haplotypes (CTG, CCG, TCG and CCC) represented $85.6 \%$ and $89.9 \%$ of the chromosomes of the controls and cases, respectively. For the VEGF haplotypes, the common alleles included CGC, TCC, CCC and CGT.

Table I: Frequency distributions of selected variables in gastric cancer cases and cancer free controls

\begin{tabular}{|c|c|c|c|c|c|}
\hline \multirow[b]{2}{*}{ Variables } & \multicolumn{2}{|c|}{ Cases $(n=171)$} & \multicolumn{2}{|c|}{ Controls $(n=353)$} & \multirow[b]{2}{*}{$P *$} \\
\hline & $\mathbf{n}$ & $\%$ & $\mathbf{n}$ & $\%$ & \\
\hline Age (years) & \multicolumn{2}{|c|}{$59.7 \pm 12.6$} & \multicolumn{2}{|c|}{$57.6 \pm 11.2$} & 0.135 \\
\hline$\leq 45$ & 24 & 14.0 & 47 & 13.3 & \\
\hline $45-59$ & 90 & 52.6 & 216 & 61.2 & \\
\hline$>59$ & 57 & 33.3 & 90 & 25.5 & \\
\hline \multicolumn{6}{|l|}{ Sex } \\
\hline Female & 56 & 32.7 & 104 & 29.5 & 0.444 \\
\hline Male & 115 & 67.3 & 249 & 70.5 & \\
\hline \multicolumn{6}{|l|}{ Ethnicity } \\
\hline Non-Hispanic White & 120 & 70.2 & 258 & 73.1 & 0.486 \\
\hline Non-White & 51 & 29.8 & 95 & 26.9 & \\
\hline \multicolumn{6}{|l|}{ Smoking status } \\
\hline Current & 34 & 19.9 & 48 & 13.6 & \\
\hline Former & 64 & 39.2 & 136 & 38.5 & 0.126 \\
\hline Never & 70 & 40.9 & 169 & 47.9 & \\
\hline \multicolumn{6}{|l|}{ Alcohol use } \\
\hline Current & 63 & 36.8 & 115 & 32.5 & \\
\hline Former & 33 & 19.3 & 45 & 12.8 & 0.037 \\
\hline Never & 75 & 43.9 & 193 & 54.7 & \\
\hline \multicolumn{6}{|l|}{ Tumor type } \\
\hline Intestinal & 101 & 59.1 & & & \\
\hline Diffuse & 20 & 11.7 & & & \\
\hline Mixed & 50 & 29.2 & & & \\
\hline
\end{tabular}

* Two-sided $\chi^{2}$ test. 
Table 2: Genotype frequencies of TGFBI and VEGF polymorphism gastric cancer cases and controls and their associations with risk of gastric cancer

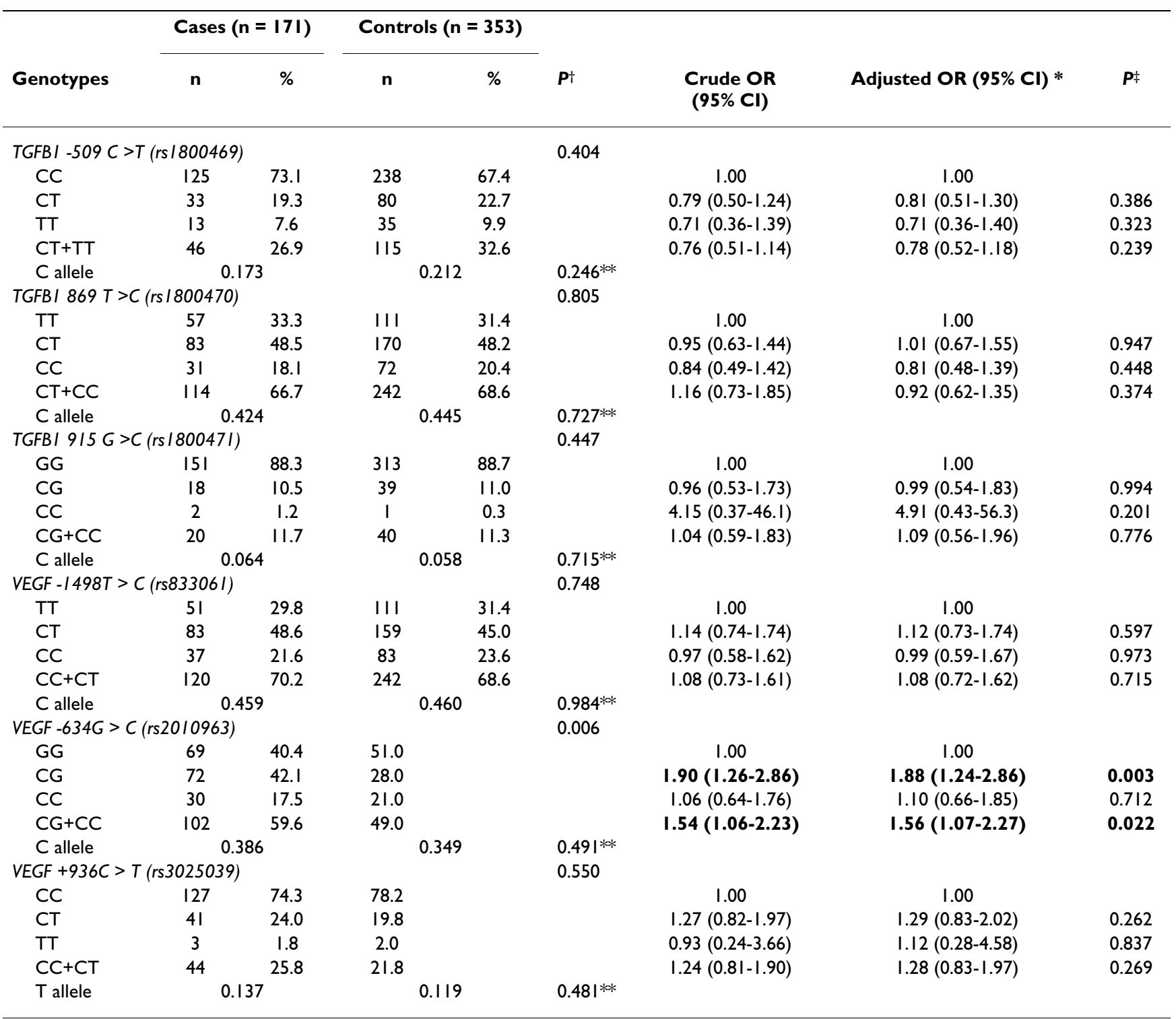

* Adjusted for age, gender, ethnicity, smoking status and alcohol status in a logistic regression model.

tTwo-sided $\chi^{2}$ test for either genotype distribution or allele frequency.

$\ddagger$ Two-sided $\chi^{2}$ test for difference in frequency distribution of genotype between cases and controls by adjusted for age, gender, ethnicity, smoking status and alcohol status.

** Two-sided $\chi^{2}$ tests for the differences in the minor allele frequencies between cases and controls

However, the frequency distributions of these haplotypes between the cases and controls was not significantly different for both TGFB1 $(P=0.759)$ and VEGF $(P=0.808)$, nor were they associated with risk of gastric cancer.

Finally, because the sample size of this study was small, we calculated FPRP for the positive findings. We found that under the assumption of a prior probability of 0.1 , the FPRP of VEGF -634CG vs. -634GG for yielded values of 0.13 , suggesting that the VEGF -634CG vs. -634GG findings was noteworthy. However, the FPRPs of VEGF -
634CG+CC vs. -634GG for all subjects, non-whites, ever smokers and never drinkers yielded values of $0.31,0.54$, 0.49 and 0.38 , respectively, which were likely to be false positive findings. Therefore, our findingds need to be validated in larger studies.

\section{Discussion}

Gastric cancer is a genetic disease developing from a multifactorial, multigenetic and multistage process $[25,26]$. It was widely accepted that both genetic and environmental factors may be involved in the etiology of gastric cancer 
Table 3: Stratification analysis of gastric cancer risk associated with the VEGF - 634 G>C genotype frequencies

\begin{tabular}{|c|c|c|c|c|c|c|c|}
\hline \multirow[b]{2}{*}{ Variables } & \multicolumn{2}{|c|}{ Cases $(n=|7|)$} & \multicolumn{2}{|c|}{ Controls $(n=353)$} & \multicolumn{2}{|c|}{ Adjusted OR (95\% CI)* } & \multirow[b]{2}{*}{$\boldsymbol{P}^{\dagger}$} \\
\hline & $\begin{array}{c}\text { GG } \\
\mathbf{N}(\%)\end{array}$ & $\begin{array}{c}\text { CG+CC } \\
\mathbf{N}(\%)\end{array}$ & $\begin{array}{c}\text { GG } \\
\mathbf{N}(\%)\end{array}$ & $\begin{array}{c}\text { CG+CC } \\
\mathbf{N}(\%)\end{array}$ & GG & $\mathbf{C G}+\mathbf{C C}$ & \\
\hline \multicolumn{8}{|l|}{ Age (years) } \\
\hline$\leq 57$ & $30(42.3)$ & $4 \mid(57.7)$ & $95(52.8)$ & 85 (47.2) & 1.00 & $1.50(0.84-2.64)$ & 0.160 \\
\hline$>57$ & $39(39.0)$ & $61(61.0)$ & $85(49.1)$ & $88(50.9)$ & 1.00 & $1.58(0.95-2.63)$ & 0.080 \\
\hline \multicolumn{8}{|l|}{ Sex } \\
\hline Female & $18(32.1)$ & 38 (67.9) & $49(47.1)$ & $55(52.9)$ & 1.00 & $1.86(0.94-3.69)$ & 0.075 \\
\hline Male & $51(44.4)$ & $64(55.6)$ & $131(52.6)$ & $118(47.4)$ & 1.00 & $1.44(0.91-2.28)$ & 0.116 \\
\hline \multicolumn{8}{|l|}{ Ethnicity } \\
\hline Hispanic White & $53(44.2)$ & $67(55.8)$ & $129(50.0)$ & $129(50.0)$ & 1.00 & $1.32(0.85-2.06)$ & 0.219 \\
\hline Non-white & $16(31.4)$ & $35(68.6)$ & $51(53.7)$ & $44(46.3)$ & 1.00 & $2.39(1.15-4.98)$ & 0.020 \\
\hline \multicolumn{8}{|l|}{ Smoking status } \\
\hline Never & $27(38.6)$ & $43(6 \mid .4)$ & 79 (46.7) & $90(53.3)$ & 1.00 & $1.33(0.75-2.38)$ & 0.336 \\
\hline Ever & $42(4 I .6)$ & $59(58.4)$ & $101(54.9)$ & $83(45.1)$ & 1.00 & $1.74(1.06-2.90)$ & 0.032 \\
\hline \multicolumn{8}{|l|}{ Drinking status } \\
\hline Never & $25(33.3)$ & $50(66.7)$ & $99(51.3)$ & $94(48.7)$ & 1.00 & $2.00(1.14-3.54)$ & 0.017 \\
\hline Ever & $44(45.8)$ & $52(54.2)$ & $81(50.6)$ & $79(49.4)$ & 1.00 & $1.24(0.74-2.07)$ & 0.411 \\
\hline
\end{tabular}

* Adjusted for age, sex, ethnicity, smoking status and alcohol status in a logistic regression model where it was appropriate.

†Two-sided $\chi^{2}$ test for the ORs obtained from the multivariate logistic regression with adjustment for age, sex, ethnicity, smoking status and alcohol status

[27]. During the multistage carcinogenesis, TGFB1 may be involved in multiple important cellular processes, play a biphasic role in carcinogenesis, and inhibit proliferation of tumors in early stages of cancers, whereas it may also promote tumor growth and metastasis in later stages of cancers $[28,29]$. Several molecular epidemiological studies have shown an association of TGFB1 SNPs with risk of

Table 4: Frequency distribution of the TGFBI and VEGF haplotype alleles between gastric cancer cases and controls and their associations with risk of Gastric Cancer

\begin{tabular}{|c|c|c|c|c|c|c|}
\hline \multirow[b]{2}{*}{ Genotypes } & \multicolumn{2}{|c|}{ Cases } & \multicolumn{2}{|c|}{ Controls } & \multirow[b]{2}{*}{$\begin{array}{l}\text { Crude OR } \\
(95 \% \mathrm{CI}) *\end{array}$} & \multirow[b]{2}{*}{$\mathbf{P} * *$} \\
\hline & $\mathbf{n}$ & $\%$ & $\mathbf{n}$ & $\%$ & & \\
\hline TGFB I alleles & \multicolumn{4}{|c|}{ (No. of variant alleles) ${ }^{\dagger}$} & & \\
\hline C-T-G & 194 & 46.0 & 387 & 40.0 & $1.29(0.12-13.7)$ & 0.830 \\
\hline C-C-G & 107 & 25.4 & 216 & 24.6 & $1.26(0.11-13.9)$ & 0.851 \\
\hline T-C-G & 56 & 13.3 & 144 & 16.4 & $1.93(0.17-21.8)$ & 0.594 \\
\hline C-C-C & 22 & 5.21 & 40 & 4.6 & $0.87(0.06-13.6)$ & 0.919 \\
\hline VEGF alleles & \multicolumn{4}{|c|}{ (No. of variant alleles $)^{\ddagger}$} & & \\
\hline C-G-C & 135 & 24.6 & 278 & 30.0 & $0.56(0.02-18.0)$ & 0.744 \\
\hline T-C-C & 115 & 20.9 & 200 & 21.6 & $0.42(0.02-13.6)$ & 0.621 \\
\hline C-C-C & 65 & 11.8 & 90 & 9.7 & $0.46(0.01-19.9)$ & 0.686 \\
\hline C-G-T & 35 & 6.4 & 45 & 4.9 & $0.25(0.0 \mathrm{I}-12.2)$ & 0.482 \\
\hline
\end{tabular}

* Calculated by using the most common haplotype as the reference. Ors represent the risk per copy of each haplotype.

† The number of TGFBI haplotype alleles; the variant (risk) alleles used for calculation were-509T, $869 \mathrm{C}$ or $915 \mathrm{C}$.

$\ddagger$ The number of VEGF haplotype alleles; the variant (risk) alleles used for calculation were -1498C, -634C or 936T.

**Two-sided $\chi^{2}$ test for the ORs obtained from the multivariate logistic regression with adjustment for age, sex, ethnicity, smoking status and alcohol status various cancers, including breast $[14,15,30,31]$, prostate $[32,33]$ and hepatocellular carcinoma $[34,35]$ and gastric cancer $[4,19]$.

The roles of $-509 \mathrm{C}>\mathrm{T},+869 \mathrm{~T}>\mathrm{C}$ and $+915 \mathrm{G}>\mathrm{C}$ SNPs in TGFB1 have been implicated in the etiology of various human cancers. For example, in high-risk Chinese populations, TGFB1 $-509 \mathrm{C}>\mathrm{T}$ was associated with a reduced risk of gastric cancer [19] and the -509T variant genotypes were found to be associated with a decreased risk of among stage I+II cases [20]. In the present study, we did not observe a significant association between TGFB1 SNPs and gastric cancer risk, partly because our study size was small. Another possible explanation is that there may be an ethnicity difference in the etiology of gastric cancer. For example, the H. pylori infection was common in Asians but not in Caucasians [36], which may interact with genetic factors. Furthermore, cancer is a disease involving multiple genes/SNPs, and therefore the combined analysis of multiple gene or haplotype-based approach might be more powerful than the analysis of single allele or locus effect [19], which requires studies with much large sample sizes. It is also likely that our results could be biased owing to possible selection biases in hospitalbased case-control studies. Therefore, larger studies are warranted to further test whether the TGFB1 variants are associated with gastric cancer risk.

Among other genetic factors, VEGF, the key mediator of angiogenesis, also plays an important role in the development of different kind of tumors, including gastric cancer. Several studies have investigated the associations between 
VEGF SNPs and risk of cancers, including breast, lung and gastric cancers $[16,17,21,22,37]$, However, the results from published studies remain inconsistent rather than conclusive. Recently, Ke Q et al [21] found that none of four potentially functional SNPs $(-2578 \mathrm{C}>\mathrm{A},-1498 \mathrm{~T}>\mathrm{C}$, $634 \mathrm{G}>\mathrm{C}$, and $+936 \mathrm{C}>\mathrm{T}$ ) of the VEGF gene or their haplotypes achieved a significant difference in their distributions between gastric cancer cases and controls in a Chinese population, whereas in a Greek study of the association between these four potentially functional SNPs in VEGF and gastric cancer risk in 100 cases and 100 controls [38], it was found that the -634CC variant genotype was associated with an increased the risk of gastric cancer with a marginal significance. However, the -634CC was shown to be associated with a significantly decreased risk of gastric cancer in a Korean population [22]. Our current study indicated that the heterozygous -634CG and the combined -634CG+CC carriers had an increased risk of gastric cancer when compared with the -634GG genotype. Again, these studies demonstrated some possible ethnic difference in the etiology of gastric cancer [19].

An obvious limitation in the present study was the lack of information on the H. pylori infection status of the subjects. Because $\mathrm{H}$. pylori infection was relatively rare in the US compared with Asian countries, these patients were not tested for $\mathrm{H}$. pylori infection upon their visit to the hospital. This defect of the study has to be corrected in future well-planned studies. Also, we observed that genetic effects were more profound in never drinkers in this study population, a phenomenon we often observed in our association studies, in which the risk associated with adverse genotypes appears to be higher in nonexposed or less exposed subjects, suggesting that the related susceptibility to cancer may be high in such subgroups. Alternatively, there may be some unknown risk factors that were not identified in these subgroups.

\section{Conclusion}

In this hospital-based case-control study of sporadic gastric cancer, our finding supports the notion that variant genotypes of the VEGF-634C $>$ G polymorphism, but not other tested SNPs, may contribute to gastric cancer risk. However, because we used a hospital-based case-control study design, the observed associations may have been biased or simply due to chances. Therefore, larger, prospective studies, particularly with the information about $H$. pylori infection, are needed to verify our findings.

\section{Abbreviations}

TGFB1: Transforming growth factor beta 1; VEGF: Vascular endothelial growth factor; LD: linkage disequilibrium; PCR-RFLP: polymerase chain reaction-restriction fragment length polymorphism; OR: odds ratio; CI: confidence interval; SNP: single nucleotide polymorphism.

\section{Competing interests}

The authors declare that they have no competing interests.

\section{Authors' contributions}

$\mathrm{XG}$ performed the genotyping work; $\mathrm{XG}, \mathrm{HZ}$, JN performed data analysis; XG, DT, QW participated in the design of the study; XG, QW wrote the manuscript; HZ, JN, DT and JA read and approved the manuscript; All authors read and approved the final manuscript for submission.

\section{Acknowledgements}

This study was in part supported by National Institutes of Health grants ROI ES 01 I740-07 and CA I3I274-0I (to Q. W.) and CA 016672 (to M. D.

Anderson Cancer Center). We thank Margaret Lung and Kathryn Tipton for their assistance in recruiting the subjects and Min Zhao, Jianzhong $\mathrm{He}$ and Kejin Xu for their laboratory assistance, and Zhensheng Liu for laboratory management and Li-E Wang for data management.

\section{References}

I. Parkin DM, Bray F, Ferlay J, Pisani P: Global cancer statistics, 2002. CA Cancer J Clin 2005, 55(2):74-108.

2. Jemal A, Siegel R, Ward E, et al.: Cancer statistics, 2008. CA Cancer J Clin 2008, 58(2):7I-96.

3. Peto J: Cancer epidemiology in the last century and the next decade. Nature 200I, 4I I (6835):390-395.

4. Li T, Cao BW, Dai Y, Cui H, Yang HL, Xu CQ: Correlation of transforming growth factor beta-I gene polymorphisms C509T and T869 C and the risk of gastric cancer in China. J Gastroenterol Hepatol 2008, 23(4):638-642.

5. Liu DH, Zhang XY, Fan DM, et al:: Expression of vascular endothelial growth factor and its role in oncogenesis of human gastric carcinoma. World J Gastroenterol 200I, 7(4):500-505.

6. Watson CJ, Webb NJ, Bottomley MJ, Brenchley PE: Identification of polymorphisms within the vascular endothelial growth factor (VEGF) gene: correlation with variation in VEGF protein production. Cytokine 2000, I 2(8): 1232-1235.

7. Renner W, Kotschan S, Hoffmann C, Obermayer-Pietsch B, Pilger E: A common $936 \mathrm{C} / \mathrm{T}$ mutation in the gene for vascular endothelial growth factor is associated with vascular endothelial growth factor plasma levels. J Vasc Res 2000, 37(6):443-448.

8. Stevens A, Soden J, Brenchley PE, Ralph S, Ray DW: Haplotype analysis of the polymorphic human vascular endothelial growth factor gene promoter. Cancer Res 2003, 63(4):8I2-816.

9. Lee KM, Park SK, Hamajima N, et al.: Genetic polymorphisms of TGF-betal \& TNF-beta and breast cancer risk. Breast Cancer Res Treat 2005, 90(2): 149-155.

10. Nikolova PN, Pawelec GP, Mihailova SM, et al.: Association of cytokine gene polymorphisms with malignant melanoma in Caucasian population. Cancer Immunol Immunother 2007, 56(3):37I-379.

II. Howell WM, Bateman AC, Turner SJ, Collins A, Theaker JM: Influence of vascular endothelial growth factor single nucleotide polymorphisms on tumour development in cutaneous malignant melanoma. Genes Immun 2002, 3(4):229-232.

12. Lin CC, Wu HC, Tsai FJ, Chen HY, Chen WC: Vascular endothelial growth factor gene-460 C/T polymorphism is a biomarker for prostate cancer. Urology 2003, 62(2):374-377.

13. Wu GY, Hasenberg T, Magdeburg R, Bonninghoff R, Sturm JW, Keese M: Association Between EGF, TGF-betal, VEGF Gene Polymorphism and Colorectal Cancer. World J Surg 2009, 33(I): 124-129.

14. Le Marchand L, Haiman CA, Berg D van den, Wilkens LR, Kolonel LN, Henderson BE: T29C polymorphism in the transforming growth factor beta I gene and postmenopausal breast cancer risk: the Multiethnic Cohort Study. Cancer Epidemiol Biomarkers Prev 2004, I3(3):4|2-4I5. 
15. Shin A, Shu XO, Cai Q, Gao YT, Zheng W: Genetic polymorphisms of the transforming growth factor-betal gene and breast cancer risk: a possible dual role at different cancer stages. Cancer Epidemiol Biomarkers Prev 2005, I 4(6): I567-I 570.

16. Kataoka N, Cai Q, Wen W, et al.: Population-based case-control study of VEGF gene polymorphisms and breast cancer risk among Chinese women. Cancer Epidemiol Biomarkers Prev 2006, I 5(6): I I 48-I I 52.

17. Lee SJ, Lee SY, Jeon HS, et al.: Vascular endothelial growth factor gene polymorphisms and risk of primary lung cancer. Cancer Epidemiol Biomarkers Prev 2005, I4(3):57I-575.

18. Kang HG, Chae MH, Park JM, et al.: Polymorphisms in TGF-beta I gene and the risk of lung cancer. Lung Cancer 2006, 52(I): I-7.

19. Jin G, Wang L, Chen W, et al: Variant alleles of TGFBI and TGFBR2 are associated with a decreased risk of gastric cancer in a Chinese population. Int J Cancer 2007, I 20(6): I330-1335.

20. Zhang $P, D i J Z$, Zhu ZZ, et al.: Association of transforming growth factor-beta I polymorphisms with genetic susceptibility to TNM stage I or II gastric cancer. Jpn J Clin Oncol 2008, 38(I 2):86I-866

21. Ke Q, Liang J, Wang LN, et al.: Potentially functional polymorphisms of the vascular endothelial growth factor gene and risk of gastric cancer. Mol Carcinog 2008, 47(8):647-65I.

22. Chae YS, Kim JG, Sohn SK, et al.: Investigation of vascular endothelial growth factor gene polymorphisms and its association with clinicopathologic characteristics in gastric cancer. Oncology 2006, 7 I(3-4):266-272.

23. An J, Liu Z, Hu Z, et al.: Potentially functional single nucleotide polymorphisms in the core nucleotide excision repair genes and risk of squamous cell carcinoma of the head and neck. Cancer Epidemiol Biomarkers Prev 2007, 16(8): 1633-1638.

24. Xianglin Yuan ZL, Liu Z, Wang L-E, Tucker SL, Mao L, Wang XS, Martel M, Komaki R, Cox JD, Milas L, Wei Q: Single Nucleotide Polymorphism at rsl982073:T869C of the TGF-betal Gene Associated with Reduced Risk of Severe Radiation Pneumonitis in Patients With Non-Small Cell Lung Cancer Treated With Definitive Radiotherapy. I Clin Oncol 2009 in press.

25. Correa P, Haenszel W, Cuello C, Tannenbaum S, Archer M: A model for gastric cancer epidemiology. Lancet 1975, 2(7924):58-60.

26. Gao L, Nieters A, Brenner H: Meta-analysis: tumour invasionrelated genetic polymorphisms and gastric cancer susceptibility. Aliment Pharmacol Ther 2008, 28(5):565-573.

27. Crandall WV, Mackner LM: Infusion reactions to infliximab in children and adolescents: frequency, outcome and a predictive model. Aliment Pharmacol Ther 2003, I7(1):75-84

28. Massague J: TGFbeta in Cancer. Cell 2008, 134(2):215-230

29. Siegel PM, Massague ]: Cytostatic and apoptotic actions of TGFbeta in homeostasis and cancer. Nat Rev Cancer 2003, 3(I I):807-82I.

30. Shu XO, Gao YT, Cai Q, et al:: Genetic polymorphisms in the TGF-beta I gene and breast cancer survival: a report from the Shanghai Breast Cancer Study. Cancer Res 2004, 64(3):836-839.

31. Dunning AM, Ellis PD, McBride S, et al.: A transforming growth factorbetal signal peptide variant increases secretion in vitro and is associated with increased incidence of invasive breast cancer. Cancer Res 2003, 63(I0):2610-26I5.

32. Ewart-Toland A, Chan JM, Yuan J, Balmain A, Ma J: A gain of function TGFBI polymorphism may be associated with late stage prostate cancer. Cancer Epidemiol Biomarkers Prev 2004, I3(5):759-764.

33. Li Z, Habuchi T, Tsuchiya N, et al.: Increased risk of prostate cancer and benign prostatic hyperplasia associated with transforming growth factor-beta I gene polymorphism at codon I 0. Carcinogenesis 2004, 25(2):237-240.

34. Migita K, Miyazoe S, Maeda Y, et al: Cytokine gene polymorphisms in Japanese patients with hepatitis B virus infection-association between TGF-betal polymorphisms and hepatocellular carcinoma. J Hepatol 2005, 42(4):505-5I0.

35. Kim YJ, Lee HS, Im JP, et al.: Association of transforming growth factor-betal gene polymorphisms with a hepatocellular carcinoma risk in patients with chronic hepatitis B virus infection. Exp Mol Med 2003, 35(3): 196-202.

36. Crew KD, Neugut Al: Epidemiology of gastric cancer. World Gastroenterol 2006, I 2(3):354-362.
37. Jacobs EJ, Feigelson HS, Bain EB, et al.: Polymorphisms in the vascular endothelial growth factor gene and breast cancer in the Cancer Prevention Study II cohort. Breast Cancer Res 2006, 8(2):R22.

38. Tzanakis N, Gazouli M, Rallis G, et al.: Vascular endothelial growth factor polymorphisms in gastric cancer development, prognosis, and survival. J Surg Oncol 2006, 94(7):624-630.

\section{Pre-publication history}

The pre-publication history for this paper can be accessed here:

\section{http://www.biomedcentral.com/1471-230X/9/77/pre}

pub
Publish with Biomed Central and every scientist can read your work free of charge

"BioMed Central will be the most significant development for disseminating the results of biomedical research in our lifetime. "

Sir Paul Nurse, Cancer Research UK

Your research papers will be:

- available free of charge to the entire biomedical community

- peer reviewed and published immediately upon acceptance

- cited in PubMed and archived on PubMed Central

- yours - you keep the copyright 